\title{
Mediação e competência em informação: proposições para a construção de um perfil de bibliotecário protagonista
}

\author{
Mediation and information literacy: propositions for the construction of a protagonist \\ librarian profile
}

\begin{abstract}
Maria Giovanna Guedes Farias
Doutora em Ciência da Informação pela Universidade Federal da Bahia - UFBA. Professora do Departamento de Ciências da Informação da Universidade Federal do Ceará - UFC. E-mail: mgiovannaguedes@gmail.com
\end{abstract}

\section{Resumo}

Apresenta proposições, a partir de um projeto de pesquisa em andamento, para o desenvolvimento de um perfil de bibliotecário protagonista, tendo como subsídios os constructos teórico-conceituais da mediação e da competência em informação. Emprega como recurso metodológico a revisão de literatura de autores clássicos e contemporâneos das temáticas em foco, bem como, a experiência docente na disciplina serviços de informação. Conclui-se que ao compreender a necessidade de integrar múltiplos saberes, utilizando os conceitos da mediação da informação, desenvolvendo um conjunto de conhecimentos e habilidades (competências), o bibliotecário pode se sentir cada vez mais preparado para atender as necessidades dos usuários, e dessa forma, sentir-se protagonista de suas atividades laborais, preparando os usuários para se tornarem, progressivamente, autônomos no acesso e uso das informações que necessitam, promovendo assim, ações que beneficiam a todos, bibliotecários e usuários dos serviços de informação.

Palavras-chave: Protagonismo social. Bibliotecário. Mediação da informação. Competência em informação.

\begin{abstract}
Presents propositions, from a research project in progress for the development of a protagonist librarian profile, with the subsidies the theoretical and conceptual constructs of mediation and information literacy. Employs as a methodological resource review of literature classics and contemporary authors on the thematic focus as well as the teaching experience in the discipline of information services. We conclude that to understand the need to integrate multiple knowledge using the concepts of information mediation, developing a set of knowledge and skills (skills), the librarian may feel increasingly prepared to meet the needs of users, and this shape, feel protagonist of their work activities, preparing users to become progressively independent in accessing and using the information they need, thus promoting actions that benefit everyone, librarians and users of information services.
\end{abstract}

Keywords: Social protagonism. Librarian. Mediation of information. Information literacy.

InCID: R. Ci. Inf. e Doc., Ribeirão Preto, v. 6, n. 2, p. 106-125, set. 2015/fev. 2016. 


\section{Introdução}

A biblioteca é um ambiente repleto de fenômenos informacionais e de sistemas complexos de interação, os quais exigem do bibliotecário uma postura proativa e inovadora para atender as necessidades dos usuários. Para tal, esse profissional precisa desenvolver consciência crítica, com foco na responsabilidade individual e coletiva, e na habilidade de tomar decisões e iniciativas, tornando-se protagonista de suas atividades laborais, o que pode acarretar, progressivamente, a disseminação da autonomia entre os usuários.

Nesta perspectiva, entende-se que esse perfil protagonista pode também ser estimulado pelo desenvolvimento de competências em informação, as quais tendem a possibilitar ao bibliotecário: antever problemas, responder prontamente aos questionamentos de forma solícita, se dispondo a aprender continuamente; utilizar os recursos disponíveis para obter sucesso nas atividades empreendidas, formulando estratégias, e mostrando-se hábil para superar obstáculos diários durante a execução de suas atividades.

Dessa forma, compreende-se como necessário analisar nesta comunicação - por meio de revisão de literatura de projeto de pesquisa em andamento - as múltiplas abordagens teóricoconceituais em torno da mediação e da competência em informação, com vistas propor um perfil de bibliotecário protagonista, visando fortalecer a atuação desse profissional, principalmente nos serviços de informação, onde ocorre o contato direto com os usuários, permitindo que a mediação explícita seja efetivada. Esse perfil protagonista tende a estimular uma atitude valorativa do labor do bibliotecário e o aprofundamento da relação com o usuário.

\section{Mediação da informação: construindo conhecimentos}

Mediar o conhecimento, com objetivo de promover o desenvolvimento do protagonismo social por meio de competências em informação, requer do mediador autoconhecimento profissional, tendo em mente que todas as ações devem ser realizadas sempre em conjunto, e de forma dialógica com todos os sujeitos envolvidos.

Para desenvolver competências em informação, o mediador, conforme Farias (2014), precisa ainda libertar-se de ideias conversadoras e estáticas, para poder sentir as demandas de um grupo, se conscientizando de seu papel na sociedade perante a responsabilidade social da área em que atua. Observa-se como primordial, no desenvolvimento desta pesquisa, apoiá-la nos fundamentos teórico-conceituais da mediação e da competência em informação como 
Mediação e competência em informação: proposições para a construção de um perfil de bibliotecário protagonista

prática social, que têm como base os pressupostos teórico-metodológicos da Ciência da Informação (CI).

Esses fundamentos em torno da pesquisa demonstram o quanto a questão social permeia todo o trabalho teórico-metodológico, e corrobora com o pensamento de Hjørland e Albrechtsen (1995, p. 400, tradução nossa), de que a "[...] Ciência da Informação deveria ser vista como uma ciência social, em vez de uma ciência cognitiva. Deveria ainda construir princípios como instrumentos para otimizar determinadas práticas sociais de natureza informativa". Além disso, reflete-se a respeito do paradigma da apropriação da informação social na CI, onde os sujeitos são protagonistas de suas próprias histórias, e procuram se apropriar para produzir conhecimento, para benefício próprio e do seu grupo.

A apropriação da informação ocorre, de acordo com Almeida Júnior (2007, 2004), no processo de mediação, se constituindo em uma ação de produção e não puramente de consumo, pressupondo uma alteração, uma transformação, uma modificação do conhecimento, onde apenas o usuário pode determinar a concretização efetiva da informação.

Entende-se que a mediação da informação serve como estímulo e exerce uma função primordial na promoção do diálogo, para indicar possíveis caminhos para o desenvolvimento de competências e, consequentemente para subsidiar o protagonismo social. Dessa forma, a mediação nesta pesquisa se aporta no paradigma social da Ciência da Informação a partir da visão de Hjørland (2004), que reflete sobre a aplicação da domain analysis (análise do domínio) na CI, como uma contribuição especial na humanização, em uma compreensão social no arcabouço de um paradigma sócio-cognitivo, e ainda do ponto de análise de Capurro (2003) nessa mesma vertente, ao explicar que um paradigma pragmático e social substituiu um paradigma físico, um paradigma baseado em enfoque cognitivo idealista e individualista. Essa substituição pode ocorrer na prática do campo de pesquisa, principalmente quando se percebe, que o conhecimento necessita ser construído coletivamente, nesse caso, com os bibliotecários.

Nessa perspectiva, a mediação pode ser vista a partir de uma abordagem sóciocognitiva, e por isso Gomes (2010, p. 87), ao tratar de mediação, ressalta que é preciso situá-la como ação vinculada à vida, ao movimento, ao processo de construção de sentidos. Isso ocorre porque o ser humano se desenvolve, segundo Vygotsky (1984) pela interação social ao adquirir a condição humana na relação com o mundo, mediado por instrumentos culturais - signo, palavra, símbolo. Segundo o autor, o conhecimento é uma produção cultural, diretamente 
relacionada à linguagem, e a mediação é a ação que se interpõe entre sujeito e objeto de aprendizagem, sendo a palavra de fundamental relevância.

Essa abordagem de Vygotsky (1991) traz como tema central o entendimento de que o ser humano se desenvolve pela interação social, o que ocorre quando o desenvolvimento cognitivo mantém estreita relação com a aprendizagem, quando há apropriação do conhecimento produzido pela humanidade e estabelecimento de relações com meio. Isso só acontece se o aprendizado for adequadamente organizado para resultar "[...] em desenvolvimento mental e por em movimento vários processos de desenvolvimento que, de outra forma, seriam impossíveis de acontecer". Por isso, o aprendizado é “[...] um aspecto necessário e universal do processo de desenvolvimento das funções psicológicas culturalmente organizadas e especificamente humanas" (VYGOTSKY, 1991, p. 61).

A mediação entre sujeitos também significa, como explica Kulhthau (1993, p. 128), “[...] permitir às pessoas fazer conexões, mover-se do concreto ao abstrato, reconhecer a necessidade de saber mais, estudar mais profundamente e obter maior compreensão", a qual pode proporcionar aos bibliotecários o desenvolvimento da consciência possível, de que trata Lucien Goldmann, e se tornarem protagonistas. Para isso, a mediação da informação é fundamental, por se tratar, conforme Kulhthau (1993, p. 128), da “[...] intervenção humana para assistir a busca de informação e aprendizagem a partir do acesso à informação e uso".

Afinal, como afirmam Ferreira e Almeida Júnior (2013), o principal resultado da mediação da informação é o conhecimento, e nesse contexto, é imprescindível a atuação da figura do mediador, aquele que interfere no momento da busca por informação de outra pessoa, e que de acordo com Belmonte (2007, p. 23) é alguém que guia, orienta, intermedeia, amplifica, organiza e desenha processos formativos, o que implica em "[...] conhecer quanto contribui a autêntica construção da obra mais complexa que podemos empreender, como a formação de uma pessoa".

A mediação ocorre no processo de interação do profissional com o usuário, no momento da comunicação. Na visão de Varela (2008, p. 36), os elementos que compõem a mediação e que vão permitir a consonância de objetivos entre o que busca o usuário e o que lhe oferta o profissional acontecem bem antes da busca, “[...] mediante um processo dialógico em que o profissional se antecipa ao desejo do usuário e organiza o estoque de informação, dialogando com este usuário potencial”. Desta forma, “[...] os elementos que compõem a mediação são os 
Mediação e competência em informação: proposições para a construção de um perfil de bibliotecário protagonista

que vão permitir a harmonia de objetivos entre o que busca o usuário e o que o profissional oferece".

Na visão de Almeida (2009, p. 16) a noção de mediação está ligada às conexões estabelecidas entre as ações sociais e as motivações (individuais/coletivas), podendo ser vista "[...] como sinônimo de processos de interlocução e/ou interação entre os membros de uma comunidade, por meio dos quais os laços de sociabilidade são estabelecidos e alimentados". Já Belmonte (2007) trabalha com a mediação em uma visão inclusiva e potencializadora do desenvolvimento integral, apresenta vários significados, e esses por sua vez, são descritos unitariamente ampliando a noção do que é mediar, acrescendo um sentido aliado à alteridade (Quadro 1):

Quadro 1 - Significados de mediação para Belmonte

\begin{tabular}{|c|l|}
\hline ACOLHER & acreditar - amar - confiar - esperar \\
\hline CONHECER & pessoa - ambiente - necessidades - vida \\
\hline COMPREENDER & empatia - dar sentido-significado \\
\hline AJUDAR & disponibilidade - cooperação \\
\hline MOTIVAR & adaptar - provocar sucesso \\
\hline POTENCIALIZAR & interiorizar- elevar nível de abstração \\
\hline PROVOCAR & questionar - desafiar - mudar - exigir \\
\hline ORIENTAR & guiar - organizar - planificar \\
\hline IMPLICAR & treinar - dar estratégias \\
\hline CONTROLAR & auto avaliar - criticar - valorar \\
\hline RELACIONAR & ver multidisciplinaridade - estruturar \\
\hline FORMAR & revisar atitudes, valores, normas \\
\hline PERSONALIZAR & dar autonomia - auto aceitação \\
\hline APLICAR & transferir- descontextualizar \\
\hline AVALIAR & sintetizar - generalizar, buscar conclusões \\
\hline
\end{tabular}

Fonte: Belmonte (2007).

Todos esses significados proporcionam elementos para fortalecer o entendimento das características que um mediador/bibliotecário deve desenvolver para empreender ações de informação, bem como para compreender quais as competências o mediador deve agregar ao seu estoque de conhecimentos.

Para contribuir para a formação e aprendizagem, é preciso intervir, mas antes de se chegar à efetiva intervenção, há outros níveis de mediação apresentados por Kuhlthau (1993), que os direcionou para os bibliotecários, quais sejam:

a) organizador: o mediador atua apenas na operacionalização do sistema; 
b) localizador: a ação aqui se concentra na localização de informações ou na resposta de questionamentos do usuário, trata-se de uma intervenção factual;

c) identificador: a mediação ocorre quando se indica fontes visando satisfazer as necessidades do usuário;

d) conselheiro: é a fase na qual o mediador procura entender o problema, para então recomendar fontes, do geral ao específico;

e) tutor: neste nível, o mediador percebe a real necessidade do usuário, estabelece um diálogo, interage, recomenda, encoraja, elabora estratégias e avança para o momento da resolução do processo contribuindo na construção do conhecimento do usuário.

Os cinco níveis de Kuhlthau demonstram que o mediador para estabelecer uma relação de intervenção com o usuário, no processo de organização do seu saber, recorre ao seu repertório intelectual, social, ideológico e afetivo, com explica Varela (2007, p. 83), que ainda explica que o mediado recebe e interfere na informação, “[...] por meio de seu próprio repertório, constituído por seus conhecimentos prévios, por suas predisposições com relação ao conteúdo e ao próprio mediador". Obviamente, que as mensagens entre esses dois sujeitos transitam por "[...] caminhos multiformes, interligados, gerando movimentos em diferentes condições, uma vez que as fontes se alteram ciclicamente e em espiral numa composição de infinitas variáveis" (p. 83).

É preciso diferenciar o mediador do intermediário, como alerta Kuhlthau (1993), pois o intermediário pode atuar como um elo entre a informação e o usuário, mas esta ação pode acontecer sem envolver qualquer interação humana. Utiliza-se alguns pressupostos de Souto (2008) para esclarecer a relação entre intermediação, mediação e interação. Este autor cita exemplos, tendo por base serviços de disseminação seletiva de informações:

a) a intermediação pode ocorrer adotando-se ou não a interação - um intermediário pode elaborar, mensalmente, uma lista dos novos títulos de publicações recebidas, organizá-la por áreas temáticas e disponibilizá-la em um site ou deixá-la em algum local físico de acesso público (bibliotecas, centros de pesquisa, corredores de universidades);

b) a presença da interação não pressupõe, obrigatoriamente, a existência da mediação - um intermediário pode interagir, ocasionalmente, com outro indivíduo e identificar que ele trabalha em uma atividade que tem relação com uma das áreas temáticas da lista organizada, contendo os novos títulos de publicações recebidas ao longo do mês. Assim, 
Mediação e competência em informação: proposições para a construção de um perfil de bibliotecário protagonista

o intermediário passa a enviar, mensalmente, ao usuário, via e-mail, a lista com os títulos das novas publicações recebidas naquela área temática;

c) a ação de interação pode estar focada na demanda ou na necessidade - um indivíduo pode interagir com um intermediário e representar para ele sua demanda. $\mathrm{O}$ intermediário, então, com foco na demanda, a partir da questão apresentada pelo indivíduo, a representa em um serviço de alerta de uma base de dados. Porém, um mediador, na mesma situação, com foco na necessidade do usuário, discutiria com o usuário, a fim de verificar se o usuário tem clareza de seu problema, o grau de conhecimento prévio já possuído em relação ao assunto, se a demanda apresentada corresponde realmente à necessidade que o motivou a iniciar a busca pela informação, etc. Se a demanda apresentada pelo usuário corresponde a sua necessidade, o mediador pode representá-la em um serviço de alerta de uma base de dados. Se a demanda apresentada pelo usuário não corresponde a sua necessidade, o mediador desenvolve um processo de mediação com o usuário, levando-o a compreender e externalizar sua necessidade de informação, para que, então, possa representá-la em um serviço de alerta de uma base de dados. Dependendo do nível de mediação proposta, o mediador pode, inclusive, ao longo do processo, atuar no sentido de facilitar a apropriação da informação.

d) o objetivo (intermediação ou mediação) da ação de interação tem relação direta com o foco (atender demanda ou necessidade) - quando um indivíduo, por exemplo, no contexto de serviços de disseminação seletiva de informações, ao desenvolver uma ação de interação, para identificar o perfil do usuário, está com foco no atendimento da demanda, ele está atuando com o objetivo de intermediar. Se o foco estiver na necessidade, ele estará atuando com o objetivo de mediar. (SOUTO, 2008, p. 62).

A mediação e atuação do mediador são consideradas por Souto como uma ação de interferência na necessidade do mediado/usuário, conduzindo-o a expressar e compreender essa necessidade, podendo facilitar o processo de busca e até de apropriação da informação. Como explicam Silva e Gomes (2013), o bibliotecário deve atrair o usuário contemplando-o como sujeito da mediação, fornecendo para ele inúmeras possibilidades de interpretação, jamais tratando-o como um objeto arbitrariamente manipulado no processo de mediação.

Por isso, o mediador/bibliotecário deve estar preparado, consciente do seu papel e poder de interferência, para elaborar estratégias a fim de ajudar o mediado na apropriação da informação. Destarte, o bibliotecário com a consciência de que medeia, precisa estar atento não 
apenas para a necessidade do usuário e para o desenvolvimento contínuo de habilidades para busca, organização e produção de informação, mas a tudo que envolve o usuário, a exemplo do contexto social, personalidade e sentimentos.

\section{Competências: habilidades para busca, organização e produção de informação}

A evolução do conceito de competência em informação foi analisada por Dudziak (2003, p. 28), que define como o "[...] processo contínuo de internalização de fundamentos conceituais, atitudinais e de habilidades necessário à compreensão e interação permanente com o universo informacional e sua dinâmica, de modo a proporcionar um aprendizado ao longo da vida". A partir da análise da evolução do conceito, a autora aponta três concepções de information literacy: a concepção da informação (com ênfase na tecnologia da informação); a concepção cognitiva (ênfase nos processos cognitivos); a concepção da inteligência (ênfase no aprendizado).

A competência em informação foi conceituada por Bruce (1997) como a habilidade em acessar, avaliar, organizar e usar a informação a fim de aprender, resolver problemas, tomar decisões em contextos formais e informais de aprendizagem, no trabalho, em casa e em ambientes educacionais, ligada ao pensamento crítico e reflexivo. Um sujeito competente em informação sabe determinar a natureza e a extensão da informação necessária; acessa-a de forma eficaz e eficiente; avalia as informações e suas fontes criticamente, e incorpora informações selecionadas em sua base de conhecimento e sistema de valores.

Segundo Le Boterf (2003) as competências nascem no âmbito trabalhista, e por isso mesmo, a empregabilidade relaciona-se à capacidade que o sujeito tem de construir competências. O autor compara a competência a um "saber-mobilizar", pois possuir conhecimentos ou capacidades não significa ser competente, é preciso saber usá-los no momento oportuno, mobilizá-los de modo pertinente, ou seja, no momento da ação.

As competências promovem, conforme Pinto Molina (2005), o pleno sucesso educativo, como o uso de fontes informacionais e dos recursos das TIC, ao utilizar as principais ferramentas da internet; conhecer as características básicas de equipamentos e infraestruturas informáticas necessárias para acessar a web; diagnosticar a informação da qual se necessita; encontrar a informação que se busca e recuperá-la com agilidade; avaliar a qualidade, autenticidade e atualidade da informação desejada, inclusive considerando alguns indicadores;

InCID: R. Ci. Inf. e Doc., Ribeirão Preto, v. 6, n. 2, p. 106-125, set. 2015/fev. 2016. 
Mediação e competência em informação: proposições para a construção de um perfil de bibliotecário protagonista

avaliar a idoneidade da informação obtida para ser utilizada em cada situação concreta; aproveitar as possibilidades de comunicação que a internet oferece; avaliar a eficácia e eficiência da metodologia empregada na busca de informação e na comunicação através da internet.

A ênfase empregada por Perrenoud (1999) para a noção de competência está direcionada para a capacidade de agir eficazmente em um determinado tipo de situação, colocando em ação e em sinergia vários recursos cognitivos complementares, entre os quais estão os conhecimentos, representações da realidade, que construímos e armazenamos a partir de nossa experiência e de nossa formação. Para o autor, as competências utilizam, integram, mobilizam conhecimentos para enfrentar um conjunto de situações complexas, implicando também uma capacitação de atualização dos saberes.

A ideia de construção de esquemas complexos de mobilização para se gerar competências de Perrenoud, entra em consonância com a definição de Kuhlthau (1999, p. 10), quando ela diz que competência é a habilidade de construir sentido por si mesmo, em um ambiente rico em informação, e para isso a autora esclarece que, para ser competente na sociedade da informação é preciso aprender a aprender no ambiente tecnológico, o que envolve: habilidade de aprender em situações dinâmicas, onde a informação está em constante mudança; habilidade de gerenciar grande quantidade de informação, quando a determinação do que significa informação suficiente é tão importante quanto localizar e selecionar informação relevante; habilidade de encontrar significado por meio da produção de sentido em mensagens diversas e numerosas, que geralmente não se encontram organizadas previamente em textos; e por fim, habilidade de construir um entendimento próprio a partir de informação incompatível e inconsistente.

Com base nessas concepções, infere-se que se trata, inicialmente, da compreensão de uma verdadeira "alfabetização digital", o que envolve cinco tipos de competências, como explica Belluzzo (2007), consideradas básicas para a sobrevivência na era do conhecimento, onde a internet parece ser um diferencial marcante: aprender a manipular símbolos, aprender a colaborar, aprender a usar a informação, aprender a resolver problemas e aprender a aprender. Conforme Varela (2011) vive-se em movimento permanente de aprendizagem, por meio de construções e transformações que realizamos, modificando-nos continuamente, à medida que nossas necessidades informacionais, cognitivas, afetivas e sociais são atendidas, o que 
transforma nosso modo de conhecer, refletir, proceder e de nos comportarmos em relação ao mundo.

O entendimento da lógica da competência passa pela compreensão do ideário histórico que norteou a formação do sujeito e os modos do trabalho ao longo dos movimentos de cunho político, econômico e social que ordenaram a sociedade. Por isso, Varela, Barbosa e Farias (2014) afirmam que, ser competente não é apenas responder a um estímulo e realizar uma série de comportamentos, mas, sobretudo ser capaz de, voluntariamente, selecionar as informações necessárias para regular sua ação ou mesmo inibir as reações inadequadas. Na realidade, essa concepção pretende superar a falta de sentido existente na mera consecução de objetivos, entretanto, a competência não é redutível aos comportamentos estritamente objetivos, mas está vinculada sempre a uma atividade humana que, seja ligada à escola ou ao trabalho, e se caracteriza por sua relação funcional com tais atividades definidas socialmente.

A manifestação das competências gira, de acordo com Le Boterf (2003, p. 37), em torno da capacidade que o profissional tem em administrar uma situação complexa, numa referência à complexidade dos processos do trabalho na atualidade, por isso, o papel do profissional será o de traçar e executar um percurso, ou seja, elaborar e conduzir um projeto, considerando " $[$.... o campo de forças e as imposições diversas e, às vezes, opostas, que constituem a complexidade". Cada fase cria uma situação nova que deve ser avaliada para dar origem a um novo percurso.

Por promover a produção de conhecimento, a competência em informação é, conforme Varela, Barbosa e Farias (2013, p. 177), considerada um processo de aprendizagem, desde que esse processo seja realizado de forma consciente, reflexivo e contextualizado, motivando o sujeito a aprender a pensar, ou seja, a internalizar “[...] conceitos, procedimentos, atitudes e valores, consistindo em mudanças cognitivas, relativamente, permanentes, resultantes das interrelações entre a nova informação, a reflexão e a experiência prévia”.

Para Gasque (2003) a competência em informação refere-se à capacidade do aprendiz de mobilizar o próprio conhecimento, que o ajuda a agir em determinada situação. Já segundo Belluzzo (2007) constitui-se em processo contínuo de interação, internalização de fundamentos conceituais, atitudinais e de habilidades específicas como referenciais à compreensão da informação e de sua abrangência, em busca da fluência e das capacidades necessárias à geração do conhecimento novo e sua aplicabilidade ao cotidiano das pessoas e das comunidades ao longo da vida, ou seja, é uma área quer requer constante aprendizado.

InCID: R. Ci. Inf. e Doc., Ribeirão Preto, v. 6, n. 2, p. 106-125, set. 2015/fev. 2016. 
Mediação e competência em informação: proposições para a construção de um perfil de bibliotecário protagonista

O bibliotecário precisa prever pontos de mediação e de aproximação com o usuário nos serviços de informação objetivando, conforme Gasque (2003), estabelecer um elo destes com os diversos signos e instrumentos de acesso à informação, aos livros, periódicos, bem como os demais materiais bibliográficos impressos e online, e também os serviços disponibilizados de forma presencial ou virtual, constituindo a motivação da existência da biblioteca.

No contexto educacional, de acordo com Accart (2012), o bibliotecário pode desempenhar dois papéis essenciais: de mediador da informação (ele é a interface indispensável entre a demanda explícita de informação e instrumentos de pesquisa diversos e às vezes complexos) e o de formador para o desenvolvimento da competência em informação, uma extensão do primeiro, isto é, o bibliotecário exerce a competência pedagógica nos cursos de capacitação para fazer com que o usuário tenha a autonomia para a pesquisa no âmbito pessoal e profissional.

Além do domínio de múltiplos saberes, para se construir um perfil de bibliotecário protagonista, Varela e Barbosa (2012), explicam que é preciso empreender ações durante a formação promovendo o desenvolvimento cognitivo e o domínio de conteúdos e metodologias profissionalizantes especializados do campo da Biblioteconomia, da Ciência da Informação e de áreas do conhecimento correlatas, de modo a solidificar essa formação, expandindo a visão crítica sobre a pluridisciplinaridade e complexidade, conduzindo o bibliotecário a focar no princípio de formação integral e integradora do indivíduo e dele com o ambiente, tendo como pilar de sustentação as demandas sociais e a função social da profissão.

É evidente a necessidade do bibliotecário de se adaptar as intensivas mudanças nas unidades de informação, características de uma sociedade geradora de novos modelos produtivos e de serviços intensivos em tecnologias de informação. Isso requer competências gerais e específicas para atender as demandas desta sociedade, a exemplo das conceituadas por Le Boterf (2003): saber agir com pertinência em cada nova situação, tomando decisões ponderadas em ocasiões imprevistas; saber integrar ou combinar saberes múltiplos e heterogêneos, procurando utilizar os recursos disponíveis para obter sucesso nas atividades empreendidas; saber mobilizar saberes e conhecimentos em um contexto profissional mobilizando conhecimentos teórico-práticos; saber transpor as barreiras físicas e cognitivas, não se limitando ao que parece ser evidente; saber aprender e aprender a aprender, colocando em prática os conhecimentos teóricos e práticos, procurando refletir a partir das experiências 
adquiridas a cada oportunidade; e saber envolver-se com a situação apresentada e se sentir estimulado a buscar cada vez mais melhorias.

Ao compreender a necessidade de integrar múltiplos saberes, desenvolvendo um conjunto de conhecimentos e habilidades, o bibliotecário pode se sentir cada vez mais preparado para exercer sua cidadania e estimular os usuários a também exercê-la, ao acessar e usar informações que necessitam, promovendo ações em benefício próprio e da comunidade.

\section{Proposições para construção de um perfil de bibliotecário protagonista}

O termo protagonista foi incorporado, conforme Perrotti e Pieruccini (2007), por movimentos de resistência, reivindicação populares e em diversos processos sociais e educacionais, com objetivo de mostrar que o protagonismo possibilita aos sujeitos uma atuação central nos contextos históricos e coletivos. Esse caráter de coletividade e de resistência, atribuído ao termo protagonismo também é ressaltado por Klein (2009, p. 10) ao esclarecer que “[...] protagonismo é um conceito cujo significado é relacional, na medida em que só pode ser compreendido em relação aos diferentes sujeitos, envolvidos num acontecimento". Os protagonistas são, segundo Perrotti e Pieruccini (2007), simultaneamente sujeitos e objetos dos processos em que estão inseridos, produtores e criadores de significados, sentidos e práticas sociais.

Desse modo, o protagonismo tem relação conceitual com o sócio-interacionismo e com o paradigma social da CI ao deslocar seus atores para o papel principal, por revelar uma dimensão pessoal e ao mesmo tempo plural de convivência com o outro, com a comunidade a qual pertence, promovendo ações de diversos níveis, inclusive informacionais, e potencializado uma dinâmica social e cultural no seu contexto, e na sociedade.

Para tanto, a dinamização ocorre por meio da intervenção, com a implantação de ações que podem ajudar o protagonista a se apropriar da informação em um movimento de produção de conhecimento e de cultura, e nessa relação os protagonistas tornam-se, como explicam Perrotti e Pieruccini (2007, p. 70), simultaneamente sujeitos e objetos dos processos em que estão inseridos, produtores e criadores de significados, sentidos e práticas sociais.

Protagonistas capacitados, corajosos e decididos de saírem da sombra dos pensamentos de outrem, expressando seus desejos, suas ideias, valorizando seu saber proveniente do senso comum, participando de forma ativa do espaço público favorecem, de acordo com Luiz (2009, 
Mediação e competência em informação: proposições para a construção de um perfil de bibliotecário protagonista

p. 70), as práticas sociais desenvolvedoras de possibilidades emancipatórias, que contribuem para a construção de uma nova cultura e de uma visão crítica do mundo, mas para isso é preciso lutar contra pensamentos arraigados e deslocados historicamente pela tutela dos que manipulam o conhecimento e o acesso a ele.

Nessa perspectiva, os protagonistas precisam ainda agir comunicativamente como "[...] falantes e destinatários, nos papéis da primeira e segunda pessoa, no mesmo nível do olhar. Contraindo uma relação interpessoal, na qual se entendem sobre algo no mundo objetivo e admitem os mesmos referentes mundanos" (HABERMAS, 2002, p. 53). Nesse processo, o sujeito pode se manter e até mesmo expandir sua identidade cultural e os valores a ela agregada, o que possibilita uma melhor compreensão da realidade social que o cerca e as relações/laços que constituem seu mundo, sua comunidade.

Esse processo comunicativo deve ser compreendido, segundo Warschauer (2006), como um sistema vivo, dinâmico, um lugar onde os sujeitos assumem papéis, que os constroem social e culturalmente em um movimento dinâmico e social com viés transformador de práticas ligadas aos modos hegemônicos de comunicação.

Ao pensar sobre o protagonismo social e seu potencial quando aliado ao poder da informação, reflete-se na visão existencialista de Sartre (1943, p. 260), que agrega valor na definição do que é ser protagonista a partir do olhar do outro ao dizer que: "eu reconheço que sou como o outro me vê", e completa que "o outro é o mediador indispensável entre mim e mim mesmo".

A visão do filósofo francês conduz ao conceito de alteridade, na relação de interação social com o outro, no contato, no processo de comunicação, e nessa mediação existente entre o "eu" e o "outro", o que levaria a um autoconhecimento, fundamental para o desenvolvimento de competências em diversos âmbitos, inclusive e principalmente, informacionais. $\mathrm{O}$ autoconhecimento seria uma forma primeira de formação de uma competência essencial, a de sujeito cognoscente. A alteridade envolve mediação quando do reconhecimento das diferenças, incide sobre um significado coletivo de informação.

Desse modo, para se construir um perfil de bibliotecário protagonista, deve-se iniciar na formação com uma educação com base na conscientização, na ação e em metodologias que prezem por autonomia e criatividade, por mudanças nas estruturas mentais dos sujeitos por meio do diálogo; uma formação com base na educação progressista e dialógica, com a 
contextualização do conhecimento, a dinamização do aprendizado que deve ocorrer de forma mútua.

A postura do bibliotecário durante o atendimento nos serviços de informação pode propiciar o aprendizado e a apropriação das informações pelos usuários, para tal algumas habilidades são relevantes como: saber ouvir os usuários dando atenção e estimulando-os a expor suas dúvidas, necessidades e desejos, sem emitir juízo de valor; procurar ser tolerante e flexível diante dos questionamentos e das diferentes posturas do outro, buscando saber se foi claro em sua exposição; utilizar linguagem acessível e respeitosa; tentar construir perguntas que permitam chegar à definição esperada do tema questionado.

Esta postura está pautada em um atendimento com visão social, dialógica e participativa, bibliotecário e usuário construindo e compartilhando experiências. Por isso, corrobora-se com Tribus (2001, p. 5) quando ele diz que as “[...] lições aprendidas a partir da experiência aparecem em nossos cérebros na forma de estruturas neurais, ou seja, conexões como relativamente persistentes entre os neurônios [...]", podendo ser usadas continuamente em novos contextos. Ainda conforme esse autor, o mediador/bibliotecário deve agir de forma criativa, gerar esse sentimento de relevância e tirar exemplos da própria experiência do usuário, pois essa capacidade de transcender o momento é uma capacidade humana única, análoga à construção de pontes de uma margem a outra, que pode se tornar a medida essencial de um atendimento bem-sucedido.

Além atuar para filtrar e facilitar o acesso e o uso da informação pelo usuário, trabalhando na busca, registro, armazenamento, recuperação, avaliação, organização, disseminação e elaboração de produtos e serviços de informação, o bibliotecário com o perfil protagonista se preocupa com a orientação e capacitação dos usuários para melhor utilização dos serviços e produtos, e procede periodicamente com pesquisas de estudo de usuários a fim de identificar novas demandas; estimulando-os no processo de aprendizagem, no hábito de leitura e da pesquisa bibliográfica, ao fortalecer a fundamentação teórica, as bases estruturais da pesquisa e da atitude científica do sujeito diante da realidade que o cerca. A figura abaixo resume algumas das características e proposições, ora refletidas nesta comunicação, objetivando se construir o perfil de um bibliotecário protagonista. 
Mediação e competência em informação: proposições para a construção de um perfil de bibliotecário protagonista

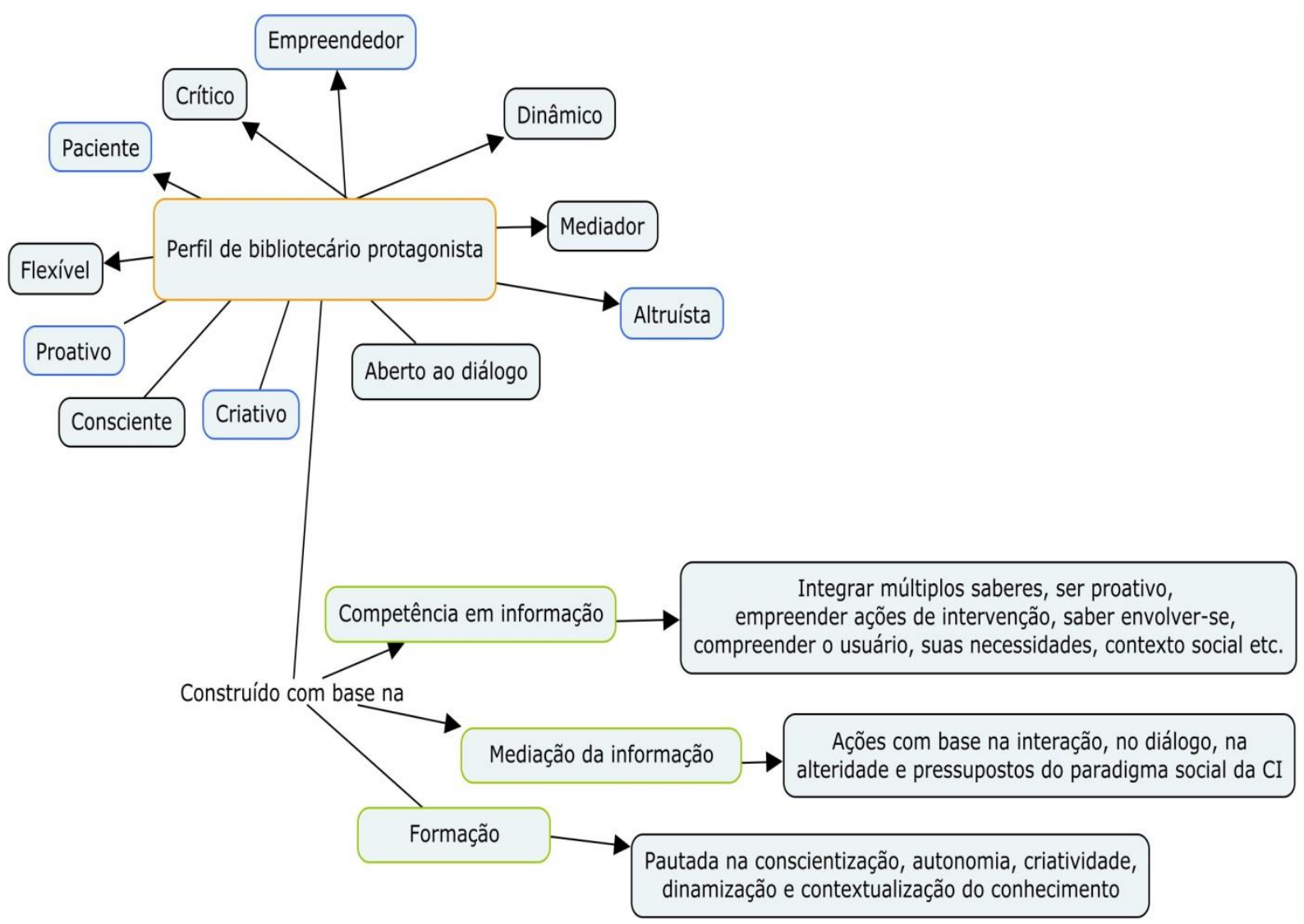

Figura 1 - Perfil do bibliotecário protagonista

Fonte: Dados da pesquisa, 2015.

Por fim, compreende-se que o bibliotecário protagonista precisa transcender e ressignificar seu fazer profissional e sua postura, pois conforme Vygotsky (1991) para se construir conhecimento é preciso uma ação partilhada significando um processo de mediação entre sujeitos, através da interação, das relações com os outros e com o meio social, por isso, qualquer função psicológica superior, se foi externa significa que ela foi social, antes de se tornar função, ela foi uma relação social entre duas pessoas. 


\section{Considerações finais}

Construir um perfil de profissional protagonista, requer do bibliotecário a compreensão da necessidade de integrar múltiplos saberes, utilizando os conceitos da mediação da informação, desenvolvendo um conjunto de conhecimentos e habilidades (competências), e se sentindo assim, cada vez mais preparado para atender as necessidades informacionais dos usuários, preparando-os para se tornarem progressivamente autônomos no acesso e uso das informações que necessitam, promovendo assim, ações que beneficiam a todos, bibliotecários e usuários dos serviços de informação. Além disso, é preciso ainda dominar as tecnologias e os recursos informacionais, e ter e transmitir confiança, interação, motivação, acolhimento, iniciativa, capacidade dialógica e organização.

Visualiza-se que o estímulo ao desenvolvimento de competências possibilita ao bibliotecário antever problemas, ir além do que é evidente, mostrando-se proativo, respondendo prontamente aos questionamentos de forma solícita, se dispondo a aprender continuamente; procurando utilizar os recursos disponíveis para obter sucesso nas atividades empreendidas, formulando estratégias, mostrando-se hábil para superar obstáculos diários durante a execução do seu labor; aprender a aprender, saber envolver-se também com a situação apresentada e se sentir estimulado a buscar cada vez mais melhorias para si, para o ambiente de trabalho e para os usuários.

Nesta perspectiva, esforços devem ser cultivados para identificar barreiras durante a formação do bibliotecário, no sentido de introduzir os princípios do protagonismo social, de propiciar aos estudantes de Biblioteconomia a reflexão da relevância deles se empoderarem verdadeiramente das informações que lhe são disseminadas no momento de aprendizado, para no futuro, colocá-las em prática junto aos usuários, seja nos serviços de informação, com a abordagem direta, ou em atividades de cunho técnico, onde se planeja e se executa com foco no usuário, uma abordagem indireta, mas pensada na mediação que se efetivará durante o atendimento.

Conclui-se que o perfil do bibliotecário protagonista apresenta as seguintes características: analisa as atividades desempenhadas, verificando o que pode ser executado de forma eficaz e eficiente em sua rotina para melhor atender, e se satisfazer enquanto profissional; empreende ações de intervenção, visando que os usuários tenham qualidade nas respostas às pesquisas solicitadas; e compreendem a necessidade de os usuários se empoderarem das 
Mediação e competência em informação: proposições para a construção de um perfil de bibliotecário protagonista

informações que lhe são disseminadas, para tornarem-se cada vez mais autônomos na busca e no acesso à informação. Anterior a isso, o bibliotecário deve ter a clareza de que suas competências devem ser potencializadas em um movimento dinâmico e constante, como desenvolvedores de significados e práticas sociais.

Ressalta-se aqui, que o prosseguimento deste projeto se dará com a pesquisa empírica em duas bibliotecas universitárias (uma tem como foco a graduação e a outra a pós-graduação), onde se analisará as competências dos bibliotecários que atuam nos serviços de informação, e, posteriormente, se verificará quais devem ser desenvolvidas para se alcançar os primeiros estágios do protagonismo social. Após essa etapa, um conjunto de ações será implantado junto a estes profissionais, visando promover a autorreflexão do que significa ter acesso e usar a informação para benefício próprio, revelando uma dimensão pessoal e ao mesmo tempo plural de convivência com o outro, com o usuário, despertando nos bibliotecários competências mediadas com vistas a desenvolver um perfil protagonista.

\section{Referências}

ACCART, J. P. Serviço de referência: do presencial ao virtual. Brasília: Briquet de Lemos, 2012. $312 \mathrm{p}$.

ALMEIDA, M. A. A produção social do conhecimento na sociedade da informação. Informação \& Sociedade: estudos, v. 19, n. 1, p. 11-18, 2009.

ALMEIDA JÚNIOR, O. F. Leitura, mediação e apropriação da informação. In: SANTOS, J. P. (Org.) A leitura como prática pedagógica na formação do profissional da informação. Rio de Janeiro: Fundação Biblioteca Nacional, 2007. p. 33-45.

Profissional bibliotecário: um pacto com o excludente. In: BAPTISTA, S. G.;

MUELLER, S. P. M. (Org.) Profissional da informação: o espaço de trabalho. Brasília: Thesaurus, 2004. p. 70-86.

BELMONTE, L. T. El professor mediador del aprendizaje. Chile: Arrayán, 2007.

BELLUZZO, R. C. B. Construção de mapas: desenvolvendo competências em informação e comunicação. 2. ed. rev. e ampl. Bauru: Cá Entre Nós, 2007.

BRUCE, C. The seven faces of information literacy. Adelaide: Auslib, 1997.

CAPURRO, R. Epistemologia e ciência da informação. In: ENCONTRO NACIONAL DE PESQUISA EM CIÊNCIA DA INFORMAÇÃO, 5., Belo Horizonte, 2003. Anais... Belo Horizonte: Escola de Ciência da Informação da UFMG, 2003. 
DUDZIAK, E. A. Information literacy: princípios, filosofia e prática. Ciência da Informação. Brasília, v. 32, n. 1, p. 23-35, jan./ abr. 2003. Disponível em:

<http://www.scielo.br/scielo.php?pid=S010019652003000100003\&script=sci_abstract\&tlng= pt>. Acesso em: 10 abr. 2012.

FARIAS, M. G. G. Análise da produção, implementação e avaliação de um modelo de mediação da informação no contexto de uma comunidade urbana. 283 f. 2014. Tese (Doutorado em Ciência da Informação) - Universidade Federal da Bahia, Instituto de Ciência da Informação, Salvador, 2014.

FERREIRA, L. E.; ALMEIDA JÚNIOR, O. F. A mediação da informação no âmbito da arquivística. Perspectivas em Ciência da Informação, Belo Horizonte, v. 18, n. 1, p. 158167, jan./mar. 2013.

GASQUE, K. C. G. D. Comportamento dos professores da educação básica na busca de informação para formação continuada. 2003. Dissertação (Mestrado em Ciência da Informação) - Departamento de Ciência da Informação, Faculdade de Estudos Sociais Aplicados, Universidade de Brasília, Brasília, 2003.

GOMES, H. F. Tendências de pesquisa sobre mediação, circulação e apropriação da informação no Brasil: estudo em periódicos e anais dos ENANCIB (2008-2009). Pesquisa Brasileira em Ciência da Informação, Brasília, v. 3, n. 1, p. 85-99, jan./dez. 2010.

HABERMAS, J. Agir comunicativo e razão destranscendentalizada. Rio de Janeiro: Tempo Brasileiro, 2002.

HJØRLAND, B. Domain analysis: a socio-cognitive orientation for information science research. Bulletin of the American Society for Information Science and Technology, v. 30, n. 3, fev./mar. 2004. Disponível em: <http://www.asis.org/Bulletin/Feb04/hjorland.html>. Acesso em: 22 abr. 2013.

; ALBRECHTSEN, H. Toward a new horizon in information science: domainanalysis. Journal of the American Society of Information Science, v. 46, n. 6, p. 400-425, 1995.

KLEIN, O. J. Para compreender o protagonismo social na construção do telejornalismo em rede. In: CONGRESSO BRASILEIRO DE CIÊNCIAS DA COMUNICAÇÃ̃O, 32., 2009, Curitiba. Anais..., Curitiba: Intercom - Sociedade Brasileira de Estudos Interdisciplinares da Comunicação, 2009.

KUHLTHAU, C. C. O papel da biblioteca escolar no processo de aprendizagem. In: VIANNA, M. M.; CAMPELLO, B.; MOURA, V. H. V. Biblioteca escolar: espaço de ação pedagógica. Belo Horizonte: EB/UFMG, 1999. p. 9-14.

. Seeking meaning: a process approach to library and information services. Norwood: Ablex, 1993.

LE BOTERF, G. Desenvolvendo a competência dos profissionais. 3. ed. rev. ampl. Porto Alegre: Artmed, 2003. 
Mediação e competência em informação: proposições para a construção de um perfil de bibliotecário protagonista

LUIZ, D. E. C. Capacitação e emancipação: uma relação possível. Revista Textos \& Contextos, Porto Alegre, v. 8 n.1 p. 68-88. jan./jun. 2009.

PERRENOUD, P. Construir as competências desde a escola. Porto Alegre: Artmed, 1999.

PERROTTI, E.; PIERUCCINI, I. Infoeducação: saberes e fazeres da contemporaneidade. In: LARA, M. L. G.; FUJINO, A.; NORONHA, D. P. (Org.). Informação e contemporaneidade: perspectivas. Recife: Néctar, 2007. p. 47-96.

PINTO MOLINA, M. Habilidades y competencias de gestión de información para aprender a aprender en el Marco del Espacio Europeo de Enseñanza Superior. Universidad de Granada, 2005. Disponível em: <http://www.um.es/dp-lenguaespa/documentos/habilidades-competencias.pdf>. Acesso em: dez. 2013.

SARTRE, J. P. L'être et le néant. Paris: Gallimard, 1943.

SILVA, J. L. C.; GOMES, H. F. A importância da mediação para a construção de uma autonomia no contexto dos estudos dos usuários da informação. Informação \& Sociedade, v. 23, p. 33-44, 2013.

SOUTO, L. F. Mediação em serviços de disseminação seletiva de informações no ambiente de bibliotecas digitais federadas. 2008. $238 \mathrm{f}$. Tese (Doutorado) - Escola de Comunicação e Artes, Universidade de São Paulo, São Paulo, 2008.

TRIBUS, M. Bridging in both directions. 2001. Disponível em: <http://www.feuersteintraining.co.uk/pdf/Bridging.pdf >. Acesso em: 20 mar. 2014.

VARELA, A. V. Estilos de aprendizagem e o ensino superior: potencializando a atitude científica. In: BARROS, D. M. V. (Org.). Estilos de aprendizagem na atualidade. Lisboa: Universidade Aberta-Portugal, 2011, v. 1, p. 1-17.

Informação, cognição e mediação: vertentes, contextos e pretextos. Revista Iberoamericana de Ciência da Informação, v. 1, p. 21-45, 2008.

Informação e construção da cidadania. Brasília: Thesaurus, 2007. v. 1. 167p.

; BARBOSA, M. The complexity of finding information in collaborative information systems: cognitive needs. In: CURRÁS, E.; LLORET ROMERO, N. (Org.). Systems science and collaborative information systems: theories, practices and new research. Hershey: IGI Global, 2012, v. 1, p. 87-120.

. FARIAS, M. G. G. Mediação em múltiplas abordagens. Informação e Informação, Londrina, v. 19, n. 2, p. 138 - 170, maio/ago. 2014.

Desenvolvimento de competências informacionais, científicas e tecnológicas: responsabilidade do ensino superior com parceria entre a docência e a biblioteca. In: BELLUZZO, R. C. B.; FERES, G. G. (Org.). Competência em informação: de reflexões às lições aprendidas. São Paulo: Febab, 2013. p. 169-202. 
VYGOTSKY, L. S. A formação social da mente: o desenvolvimento dos processos psicológicos superiores. 4. ed. São Paulo: Martins Fontes, 1991.

A construção do pensamento e linguagem. São Paulo: Martins Fontes, 1984.

WARSCHAUER, M. Tecnologia e inclusão social: a exclusão social em debate. São Paulo: Ed. Senac, 2006.

Artigo submetido em: 30 jul. 2015

Artigo aceito em: 08 set. 2015 